\title{
Effect of Irrigation Systems and Soil Conditioners on the Growth and Essential Oil Composition of Rosmarinus officinalis L. Cultivated in Egypt
}

\author{
Elsayed Omer ${ }^{1, *}$, Saber Hendawy ${ }^{1}$, Abdel Nasser ElGendy ${ }^{1}{ }^{1}$, Alberto Mannu ${ }^{2,3}{ }^{\oplus}$, \\ Giacomo L. Petretto ${ }^{2}(1)$ and Giorgio Pintore ${ }^{2, *}$ \\ 1 Medicinal and Aromatic Plants Research Department, National Research Centre, Dokki 12622, Cairo, Egypt; \\ hendawysaber@yahoo.com (S.H.); aggundy_5@yahoo.com (A.N.E.) \\ 2 Department of Chemistry and Pharmacy, Sassari University, 07100 Sassari, Italy; \\ alberto.mannu@unito.it (A.M.); gpetretto@uniss.it (G.L.P.) \\ 3 Department of Chemistry, University of Turin, via Pietro Giuria 7, 10125 Turin, Italy \\ * Correspondence: sayedomer2001@yahoo.com (E.O.); pintore@uniss.it (G.P.)
}

Received: 3 July 2020; Accepted: 13 August 2020; Published: 15 August 2020

check for updates

\begin{abstract}
A relevant improvement of the cultivar conditions of Rosmarinus officinalis L. in desert areas was achieved by a specific combination between an irrigation system and soil conditioner. A drastic reduction in water employment was obtained without affecting the quality of the plants, which was determined by monitoring the growth parameters and essential oil characteristics. In particular, the effect of surface and subsurface drip irrigation systems and different soil conditioners on the growth parameters, yield, and essential oil constituents of rosemary plants was assessed. Field experiments at the Agricultural Research Station (Al-Adlya farm), SEKEM Group Company, El-Sharkiya Governorate, Egypt, conducted over the two seasons, revealed the effectiveness of subsurface irrigation systems in obtaining better performances, especially in terms of saving water. The combination of subsurface irrigation and the conditioner HUNDZ soil with bentonite showed the maximum mean values of growth characteristics compared with other soil amendments during both seasons. The possibility to employ a water-saving irrigation system at the subsurface level without any drawback in the resulting plants was also explored in terms of molecular composition. Gas chromatography-mass (GC-MS) analysis of the essential oils extracted from plants grown under different irrigation conditions revealed a comparable composition in both cases. The quality of the system that showed the best performance was also confirmed by the comparable yield of the essential oil.
\end{abstract}

Keywords: Rosmarinus officinalis L.; surface and subsurface drip irrigation; bentonite; HUNDZ conditioner; essential oil

\section{Introduction}

Water is a very important economical resource and it represents a major limiting factor for sustainable agriculture in arid and semi-arid regions [1]. In Egypt, all cultivated lands are characterized by an arid or semi-arid climate and the water required for agricultural and horticultural crops is obtained mainly through irrigation systems which consume about $83 \%$ of the country's available fresh water [2]. The demanding need of water is in part determined by the low-field application efficiency [3], which in most traditional irrigation methods is less than 50\% or lower, often under 30\% [4]. Thus, the interest in developing and adopting new and efficient water irrigation systems, particularly in arid and semi-arid regions, is very high [5]. In areas like Egypt, this problem is particularly evident, as the growing competition for optimizing the scarce water resources has led to the development of new techniques for maximizing the water use efficiency and improving crop yields and quality [6]. 
The first step toward the optimization of water demand should consist of reducing the current excessive application of water in agricultural lands. This generally entails losses due to the surface run-off from the field and to the deep percolation below the root zone within the field [7]. Both phenomena are difficult to control under a furrow irrigation system, where a large volume of water is applied at a single instance. Alternative water application methods, such as a drip irrigation system, have some advantages, as they have a more uniform irrigation distribution, more precise control of the amount of water employed, decrease nutrient leaching, reduce subsurface drainage, better control the soil salinity, and increase the yield of growth parameters [8-11]. Nevertheless, the drip irrigation system has some drawbacks as its cost, which can reach USD $2470 \mathrm{ha}^{-1}$ [12]. Additionally, drip irrigation requires the presence of small and diffused irrigation systems to saturate the soil and fulfill plant water requirements. In addition, there are specific problems related to the management of sandy soils, including their excessive permeability and low water and nutrient holding capacities [13]. The water use efficiency can be increased by using a subsurface drip irrigation system, which is characterized by a reduced soil and plant surface evaporation and allows to irrigate exclusively the root zone or the partial root zone as opposed to sprinkler irrigation where the entire field area is wetted [14-16]. Additionally, a subsurface drip irrigation allows for the improvement in the salinity management and the water use efficiency. Phene [8] and Oron [17] reported that a surface drip irrigation decreases the accumulation of salts at the root zone level of plants, producing an improved yield and fruit quality. Oliveira reported that a subsurface drip irrigation reduces the evaporation from the soil and increases the wetted soil volume and surface area more than surface systems, allowing a deeper rooting pattern [18]. Subsurface drip irrigation systems have been successfully employed for the irrigation of a wide range of crop patterns [19] but, on the other hand, no studies have been conducted under intensive field crops. The use of these modern irrigation systems (surface and subsurface drip) in cultivating ornamental plants has improved the growth and quality of flowers [20,21]. It is known that drip irrigation can increase the water use efficiency in crop production. Even more efficient in terms of water amount needed is the subsurface drip irrigation [22], which differs from the standard drip irrigation in that the lateral pipes are buried below the ground surface [23]. In subsurface drip irrigation, the water losses through evaporation and deep percolation are minimized, resulting in an increased overall efficiency and nutrient conservation. Lamm and coworkers achieved water savings of $\sim 25 \%$ with respect to classical techniques in the case of corn cultivation [24]. Nevertheless, it is impossible to establish a priori the best irrigation mechanism in terms of general efficiency, and a comparison between the available irrigation techniques is mandatory before choosing the more appropriate system. In this context, the assessment of the best combination between irrigation systems and soil conditioners for the cultivation of Rosmarinus officinalis L. (Lamiaceae) in Egypt is herein reported for the first time. Rosmarinus officinalis is a flowering plant widely present in Mediterranean countries, southern Europe and in the littoral region through Minor Asia areas. Several studies on the chemical composition of phenolic compounds [25], as well as on the steam distilled essential oils (EOs) from plants belonging to different regions in the world, have been reported [26,27]. Many aspects of the EO of Rosmarinus officinalis have been the object of research, because of its antioxidant [28,29], antibacterial [30,31], anti-inflammatory [32], antinociceptive [33], and antifungal activity [34,35], as well as its toxicity toward insects [36]. Additionally, in recent years EOs of Rosmarinus officinalis have been commercialized as pest control products [37]. A detailed study about several growth parameters, including the EO composition, is herein presented. In particular, the growth, yield, and chemical composition of the EO extracted from different parts of the plant will be described and related to the specific irrigation system (surface or subsurface drip irrigation) and soil conditioner. The possibility to optimize, in terms of water harvesting, rosemary cultivation in arid lands is thus explored. In order to reach such a target, the following parameters have been monitored and related to irrigation systems and soil conditioners: plant height, branch number, weight yield of fresh and dry herb, EO content and yield. 


\section{Materials and Methods}

\subsection{Location of the Experiments}

The field trial was carried out at the Agricultural Research Station (Al-Adlya farm), SEKEM Company, Sharkiya Governorate, Egypt (80 km east of Cairo), during two seasons of 2012/2013-2013/2014. The determination of some physical and chemical properties of soil samples and the analyses of the irrigation water systems were conducted according to standard procedures already described and represented in Table 1. Additionally, some meteorological data and evapotranspiration data during the growing season are presented in Table 1.

Table 1. Geographic positions, climatic data and specifications of the soil for the Al-Adlya site.

\begin{tabular}{|c|c|c|c|c|}
\hline \multicolumn{2}{|c|}{ Environmental Data } & \multicolumn{3}{|c|}{ Soil Properties } \\
\hline Latitude (N) & 30.397098 & O.M.\% & & 1.38 \\
\hline Longitude (E) & 31.551662 & $\mathrm{CaCO}_{3} \%$ & & 4 \\
\hline Elevation (m) & 13 & $\mathrm{pH}(1: 2: 5)$ & & 8.28 \\
\hline Distance $(\mathrm{km})^{\mathrm{a}}$ & 80 & $\mathrm{EC}(\mathrm{dS} / \mathrm{m})$ & & 2.72 \\
\hline Direction & North-East & \multirow{4}{*}{$\begin{array}{l}\text { Available macronutrients } \\
\qquad(\mathrm{mg} / 100 \mathrm{~g} \text { soil })\end{array}$} & $\mathrm{Ca}^{++}$ & 369 \\
\hline Max. temperature ${ }^{b}$ & 27.4 & & $\mathrm{Mg}^{++}$ & 100 \\
\hline Min. temperature $\mathrm{b}$ & 16.3 & & $\mathrm{Na}^{+}$ & 231 \\
\hline $\mathrm{T}^{\mathrm{b}}$ & 11.1 & & $\mathrm{P}$ & 1.82 \\
\hline Relative humidity (\%) b & 56.7 & \multirow{5}{*}{$\begin{array}{l}\text { Available micronutrients } \\
\text { (ppm) }\end{array}$} & K & 27 \\
\hline Average temperature ${ }^{b}(C)$ & 23.6 & & $\mathrm{Fe}$ & 10.2 \\
\hline RH $(\%)$ & 61 & & $\mathrm{Mn}$ & 13.4 \\
\hline WS (Km/day) & 144.7 & & $\mathrm{Zn}$ & 2.6 \\
\hline PSSH (hr) & 9.3 & & $\mathrm{Cu}$ & 0.3 \\
\hline Coarse sand $(\%)$ & 76.8 & & & \\
\hline Silt $(\%)$ & 8 & & & \\
\hline Clay (\%) & 15.2 & & & \\
\hline Texture & Sand loamy & & & \\
\hline
\end{tabular}

${ }^{a}$ From Cairo; ${ }^{b}$ year average. $\mathrm{RH}=$ relative humidity; WS = wind speed; PSSH = potential sunshine hours.

\subsection{Experimental Design}

The field experiment was carried out as a split plot design. The split plot design pertains to the factorial family designs, and it well fits with the case-study herein considered. It has been developed for situations where two different types of factors are considered: one hard to change and another easier to modify [38]. Herein, the following factors were considered: two irrigation systems (hard to change factors), and four soil amendments (one control and three treatments, easy to change factors).

The irrigation systems (surface and subsurface irrigation) were placed in block 1, while the soil conditioners treatments (control (0), HUNDZ soil ( $3 \%)$, bentonite ( $3 \%$ ) and HUNDZ soil + bentonite) were placed in block 2. A total of eight experiments were planned, as a result of the two block combination, and performed.

The HUNDZ soil and bentonite conditioners were added to the soil preparation at a concentration of $3 \%$. The plants' row spacing was $0.75 \mathrm{~m}$ and the distance between each plant was $0.25 \mathrm{~m}$ in plots with area of $15 \mathrm{~m}^{2}(3 \times 5 \mathrm{~m})$.

\subsection{Statistical Analysis}

The data of each season were statistically analyzed separately according to Cochran and Cox. The differences between the means of the treatments were considered significant when they were more than Least Significant Differences (LSD) at 5\%. The data were subjected to a one-way ANOVA test (MS DOS/Costat Exe Program). 


\subsection{Irrigation Setup}

The drip irrigation lines were twin-wall drip tapes (GR), with outlets spaced every $0.5 \mathrm{~m}$. Standard drippers of $4 \mathrm{~L} / \mathrm{h}$ discharge at a 1.5 bar working pressure were used. The drip irrigation lines were laid above and under the ridges of plant rows, and the installation depth of the subsurface drip lines was $0.20 \mathrm{~m}$.

\subsection{Plant Materials}

Rosmarinus officinalis L. Spanish rosemary cuttings (at age 2 years) were imported from Bionorica Company, Germany.

\subsection{Cultivation}

The cuttings were cultivated in the nursery in foam trays filled with a mixture of sand:compost:petmos (1:1:1 volume) in the first week of October. The cuttings were covered with 100-micron white plastic mulch after cultivation and then irrigated every 3-5 days by dripping irrigation. After 45 days, the plastic mulch cover was removed, and after the cuttings showed white roots $(2-5 \mathrm{~cm})$ they were deemed ready for transferring into the permanent soil in the open field. The irrigation was performed as needed until the plants generated the first two true leaves stage, where the irrigation treatments were applied. The experimental soils were supplied with $20 \mathrm{~m}^{3} / \mathrm{Fad}$. $\left(\right.$ Fad. $\left.=4200 \mathrm{~m}^{2}\right)$ of mature compost. Routine agricultural practices were carried out as usually practiced in rosemary cultivation. The data for the growth characters, yield, EO and its chemical constituents for all treatments were obtained during two harvests in June and in August in the two seasons. The data measurements included the plant height $(\mathrm{cm})$, number of branches/plants, and fresh and dry weights of the herb (g/plant).

\subsection{EO Production}

The EO percentage of each replicate at the two harvests was determined in the air-dried herb according to Guenther (1995) and expressed as $\mathrm{mL} / 100 \mathrm{~g}$, while the EO yield was expressed as $\mathrm{mL} /$ plant and $\mathrm{L} / \mathrm{m}^{2}$.

The extraction procedure for the essential oil was carried out according to a previous literature data [39]. A sample of plant aerial part weighing $300 \mathrm{~g}$ was subjected to hydro-distillation using a Clevenger-type apparatus for $2 \mathrm{~h}$. The extraction was repeated twice, and the obtained EO was collected separately, dried over anhydrous sodium sulfate $\left(\mathrm{Na}_{2} \mathrm{SO}_{4}\right)$ and then stored at $4{ }^{\circ} \mathrm{C}$ in amber glass vials until analysis.

\subsection{Qualitative and Quantitative Analyses of EOs}

Rosemary EO samples were analyzed through GC-MS with a Hewlett Packard 5890 GC equipped with a Hewlett Packard 5971 MS system operating in the EI mode at $70 \mathrm{eV}$. The EO separation was performed on an HP-5 capillary column $(30 \mathrm{~m} \times 0.25 \mathrm{~mm}$, film thickness $0.17 \mu \mathrm{m})$. The following temperature program was used: $60^{\circ} \mathrm{C}$ hold for $3 \mathrm{~min}$, then increased by $4{ }^{\circ} \mathrm{C} / \mathrm{min}$ until it reached $210{ }^{\circ} \mathrm{C}$, then held at $210{ }^{\circ} \mathrm{C}$ for $15 \mathrm{~min}$, then increased by $10{ }^{\circ} \mathrm{C} / \mathrm{min}$ to $300{ }^{\circ} \mathrm{C}$, and finally held at $300{ }^{\circ} \mathrm{C}$ for $15 \mathrm{~min}$. Helium was used as the carrier gas at a constant flow of $1 \mathrm{~mL} / \mathrm{min}$ for both columns. The data were analyzed using Agilent Chemstation software and the identification of the individual components was performed by comparison with the co-injected pure compounds and by matching the MS fragmentation patterns and retention indices with the data reported in libraries or the literature data (NIST/EPA/NIH 2008; HP1607 purchased from Agilent Technologies and Adams, 2011). The relative proportion percentages of the EO constituents were obtained by peak area normalization [40]. 


\section{Results and Discussion}

Rosmarinus officinalis L. plants grown in Egypt, at Agricultural Research Station (Al-Adlya farm), SEKEM group Company, El-Sharkiya Governorate.

The environmental characteristics, as well as the climatic and physical data of the soil employed for the present research, are reported in Table 1.

\subsection{Plant Height (cm) and Branch/Plant Number}

At first, the growth factors as plant height and number of branches were monitored for plant growth with surface or subsurface irrigation and with conditioners. The aim of this first analysis was to check how different irrigation systems and conditioners affect the overall growth of the plants. The results of the monitoring conducted over two seasons are reported in Table 2.

Table 2. Fresh herb of Rosmarinus officinalis plants grown under different drip irrigation systems with different sources of soil conditioners. The medium values of three measurements are reported for each measurement.

\begin{tabular}{|c|c|c|c|c|c|c|c|}
\hline \multirow{3}{*}{\multicolumn{2}{|c|}{ Treatment }} & \multicolumn{6}{|c|}{ Fresh Weight (g/Plant) } \\
\hline & & \multirow{2}{*}{\multicolumn{2}{|c|}{$\begin{array}{c}\text { First Season } \\
\text { 2nd Cut } \\
\text { Mean }( \pm)\end{array}$}} & \multirow{2}{*}{$\begin{array}{c}\text { 1st Cut } \\
\text { Mean }( \pm)\end{array}$} & \multicolumn{3}{|c|}{ Second Season } \\
\hline & & & & & $\begin{array}{l}\text { 2nd Cut } \\
\text { Mean }( \pm)\end{array}$ & $\begin{array}{c}\text { 1st Cut } \\
\text { Mean }( \pm)\end{array}$ & $\begin{array}{l}\text { 2nd Cut } \\
\text { Mean }( \pm)\end{array}$ \\
\hline \multirow{4}{*}{ Surface } & $\mathrm{C}$ & $35.89(1.65)$ & $6.98(0.80)$ & $42.87(0.60)$ & $46.93(2.43)$ & $9.67(0.81)$ & $56.61(1.15)$ \\
\hline & $\mathrm{H}$ & $36.33(2.67)$ & $10.12(1.76)$ & $46.46(0.64)$ & $48.48(1.41)$ & $12.02(0.67)$ & $60.49(0.52)$ \\
\hline & $\mathrm{BIO}$ & $35.67(2.00)$ & $9.40(1.06)$ & $45.07(0.67)$ & $46.45(2.98)$ & $14.04(1.70)$ & $60.49(0.91)$ \\
\hline & $\mathrm{H}+\mathrm{B} 10$ & $38.55(2.04)$ & $8.62(0.57)$ & $47.17(1.03)$ & $51.39(1.43)$ & $10.15(0.98)$ & $61.54(0.32)$ \\
\hline \multicolumn{2}{|c|}{ Surface irrigation } & $36.61(2.09)$ & $8.78(1.05)$ & $45.39(0.74)$ & $25.89(0.22)$ & $13.79(0.37)$ & $59.78(0.10)$ \\
\hline \multirow{4}{*}{ Subsurface } & $\mathrm{C}$ & $38.78(1.71)$ & $10.52(0.84)$ & $49.30(0.62)$ & $50.41(3.35)$ & $13.29(1.26)$ & $63.70(1.48)$ \\
\hline & $\mathrm{H}$ & $41.22(1.50)$ & $12.95(1.30)$ & $54.18(0.14)$ & $54.40(3.12)$ & $17.49(1.14)$ & $71.89(1.40)$ \\
\hline & $\mathrm{BIO}$ & $39.33(2.33)$ & $15.92(1.75)$ & $55.25(0.41)$ & $53.66(3.01)$ & $19.41(1.38)$ & $73.07(1.15)$ \\
\hline & $\mathrm{H}+\mathrm{B} 10$ & $42.33(1.86)$ & $11.84(1.72)$ & $54.17(0.10)$ & $53.51(3.66)$ & $17.76(1.42)$ & $71.27(1.58)$ \\
\hline \multicolumn{2}{|c|}{ Subsurface } & $40.42(1.85)$ & $12.81(1.40)$ & $53.22(0.32)$ & $28.58(0.77)$ & $17.43(0.32)$ & $69.98(0.32)$ \\
\hline \multirow{4}{*}{ Soil conditioners } & $\mathrm{C}$ & $37.33(1.68)$ & $8.75(0.82)$ & $46.09(0.61)$ & $26.40(0.15)$ & $13.92(0.33)$ & $60.15(0.13)$ \\
\hline & $\mathrm{H}$ & $38.78(2.08)$ & $11.54(1.53)$ & $50.32(0.39)$ & $27.42(0.80)$ & $16.19(0.29)$ & $66.19(0.36)$ \\
\hline & $\mathrm{BIO}$ & $37.50(2.17)$ & $12.66(1.40)$ & $50.16(0.54)$ & $26.52(0.61)$ & $16.72(0.05)$ & $66.78(0.50)$ \\
\hline & $\mathrm{H}+\mathrm{B} 10$ & $40.44(1.95)$ & $10.23(1.15)$ & $50.67(0.57)$ & $28.60(0.41)$ & $15.61(0.11)$ & $66.41(0.21)$ \\
\hline \multicolumn{2}{|c|}{ LSD $5 \%$ irrigation } & ns & 1.69 & 2.08 & ns & 2.83 & 2.46 \\
\hline \multicolumn{2}{|c|}{ LSD $5 \%$ soil conditioners } & ns & 0.2 & 2.94 & ns & ns & 3.48 \\
\hline \multicolumn{2}{|c|}{ LSD 5\% Interaction } & ns & ns & ns & ns & ns & ns \\
\hline
\end{tabular}

$\mathrm{C}=$ control, $\mathrm{H}=\mathrm{HUNDZ}$ soil, $\mathrm{BIO}$. = bentonite, $\mathrm{H}+\mathrm{B} 10=\mathrm{HUNDZ}$ soil + bentonite, $\Delta=$ standard deviation, $\mathrm{LSD}=$ least significant differences, $\mathrm{ns}=$ not significant.

Looking at the plot reported in Figure 1, it is possible to notice that no significant variation in terms of the plant height and number of branches occurred by changing the irrigation system or growing the plants with different sources of soil conditioners. This suggests that a more water-saving subsurface irrigation system can be employed for rosemary cultivation without any loss in terms of growth parameters. The same analysis was conducted in terms of different soil conditioners: HUNDZ soil combined with bentonite showed the maximum mean values in terms of plant height and branch number under a subsurface irrigation system. The correlation between the growth parameters and irrigation systems, herein presented for the first time, represents an important novelty for the rosemary growth, as it allows the optimization of the cultivation conditions in arid lands. The data reported in Table 2 suggest the possibility of growing high-quality Rosmarinus officinalis and employing less water than usual. Similar results were reported by Phene [41], who observed significant differences between subsurface drip and surface irrigation systems for tomatoes crops. The finding of significative differences between the two irrigation systems was not obvious. In fact, Bidondo reported no significant variations between the two irrigation systems regarding their phenological responses [42]. 


\section{Growth parameters during two seasons}

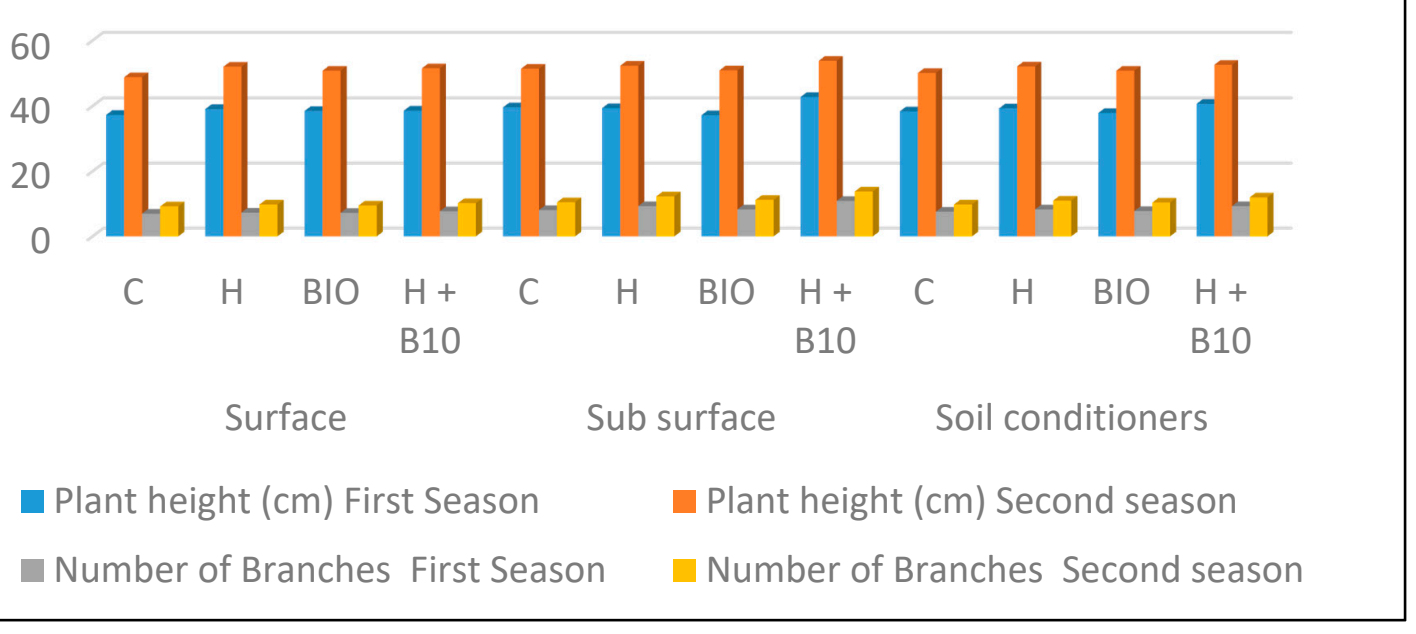

Figure 1. Plant height and number of branches/plants of Rosmarinus officinalis plants grown under different drip irrigation systems with different sources of soil conditioners. Each value reported represents the media of three measurements.

\subsection{Fresh Herb and Dry Weights (g/Plant and $\mathrm{kg} /$ Fad.)}

In order to assess the effect of the different irrigation systems and soil conditioners on the growth of the Rosmarinus officinalis L., a design of experiments (DoE) approach was used to highlight the main factors influencing the fresh herb and dry weight (Tables 2 and 3), and cultivated area (Tables 4 and 5).

Table 3. Dry herb of Rosmarinus officinalis plants grown under different drip irrigation systems with different sources of soil conditioners. The medium values of three measurements are reported for each measurement.

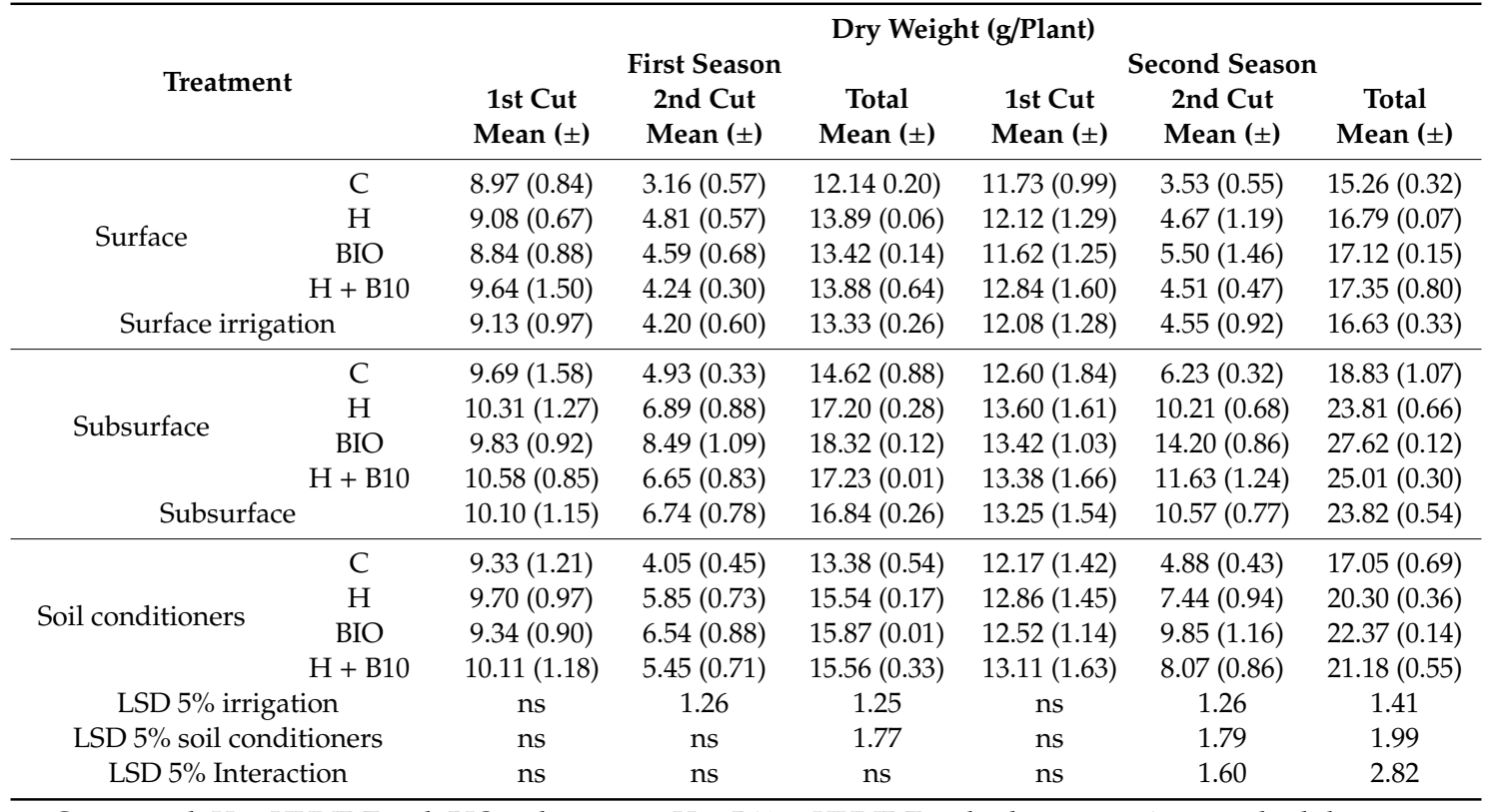

$\mathrm{C}=$ control, $\mathrm{H}=\mathrm{HUNDZ}$ soil, BIO. = bentonite, $\mathrm{H}+\mathrm{B} 10=\mathrm{HUNDZ}$ soil + bentonite, $\Delta=$ standard deviation, $\mathrm{LSD}=$ least significant differences, $\mathrm{ns}=$ not significant. 
Table 4. Fresh yield of Rosmarinus officinalis plants grown under different drip irrigation systems with different sources of soil conditioners. The medium values of three measurements are reported for each measurement.

\begin{tabular}{|c|c|c|c|c|c|c|c|}
\hline \multirow{3}{*}{\multicolumn{2}{|c|}{ Treatment }} & \multicolumn{6}{|c|}{ Fresh Yield (kg/Fad.) } \\
\hline & & \multirow{2}{*}{$\begin{array}{c}\text { 1st Cut } \\
\text { Mean }( \pm)\end{array}$} & \multirow{2}{*}{$\begin{array}{c}\text { First Season } \\
\text { 2nd Cut } \\
\text { Mean }( \pm)\end{array}$} & \multirow{2}{*}{$\begin{array}{c}\text { Total } \\
\text { Mean }( \pm)\end{array}$} & \multicolumn{3}{|c|}{ Second Season } \\
\hline & & & & & Mean ( $( \pm)$ & Mean $( \pm)$ & Mean $( \pm)$ \\
\hline \multirow{4}{*}{ Surface } & $\mathrm{C}$ & $825.5(37.8)$ & $160.6(18.3)$ & $986.1(13.8)$ & $\begin{array}{l}1079.4 \\
(55.8)\end{array}$ & $222.5(18.5)$ & $\begin{array}{l}1301.9 \\
(26.3)\end{array}$ \\
\hline & $\mathrm{H}$ & $835.7(61.3)$ & $232.8(40.4)$ & $\begin{array}{l}1068.5 \\
(14.8)\end{array}$ & $\begin{array}{l}1115.0 \\
(32.4)\end{array}$ & $276.3(15.4)$ & $\begin{array}{l}1391.3 \\
(12.0)\end{array}$ \\
\hline & $\mathrm{BIO}$ & $820.4(46.0)$ & $216.2(24.3)$ & $\begin{array}{l}1036.6 \\
(15.3)\end{array}$ & $\begin{array}{l}1068.5 \\
(68.6)\end{array}$ & $323.0(39.0)$ & $\begin{array}{l}1391.3 \\
(20.9)\end{array}$ \\
\hline & $\mathrm{H}+\mathrm{B} 10$ & $886.7(46.8)$ & $198.1(13.2)$ & $\begin{array}{l}1084.9 \\
(23.8)\end{array}$ & $\begin{array}{l}1181.9 \\
(32.8)\end{array}$ & $233.5(22.4)$ & $1415.5(7.3)$ \\
\hline \multicolumn{2}{|c|}{ Surface irrigation } & $842.1(48.0)$ & $201.9(24.0)$ & $\begin{array}{l}1044.0 \\
(16.9)\end{array}$ & $\begin{array}{l}1111.2 \\
(47.4)\end{array}$ & $263.8(23.8)$ & $\begin{array}{l}1375.0 \\
(16.7)\end{array}$ \\
\hline \multirow{4}{*}{ Subsurface } & $\mathrm{C}$ & $891.9(39.4)$ & $241.9(19.3)$ & $\begin{array}{l}1133.8 \\
(14.2)\end{array}$ & $\begin{array}{l}1159.4 \\
(77.0)\end{array}$ & $305.6(29.0)$ & $\begin{array}{l}1465.0 \\
(33.9)\end{array}$ \\
\hline & $\mathrm{H}$ & $948.1(34.6)$ & $297.9(29.9)$ & $1246.1(3.3)$ & $\begin{array}{l}1251.2 \\
(71.8)\end{array}$ & $402.3(26.1)$ & $\begin{array}{l}1653.6 \\
(32.3)\end{array}$ \\
\hline & $\mathrm{BIO}$ & $904.7(53.7)$ & $366.0(40.2)$ & $1270.7(9.5)$ & $\begin{array}{l}1234.2 \\
(69.3)\end{array}$ & $446.4(31.8)$ & $\begin{array}{l}1680.7 \\
(26.5)\end{array}$ \\
\hline & $\mathrm{H}+\mathrm{B} 10$ & $973.7(42.7)$ & $272.3(39.5)$ & $1245.9(2.3)$ & $\begin{array}{l}1230.8 \\
(84.2)\end{array}$ & $408.5(32.7)$ & $\begin{array}{l}1639.3 \\
(36.4)\end{array}$ \\
\hline \multicolumn{2}{|c|}{ Subsurface } & $929.6(42.6)$ & $294.5(32.2)$ & $1224.1(7.3)$ & $\begin{array}{l}1218.9 \\
(75.6)\end{array}$ & $390.7(29.9)$ & $\begin{array}{l}1609.6 \\
(32.3)\end{array}$ \\
\hline \multirow{4}{*}{ Soil conditioners } & $\mathrm{C}$ & $858.7(38.6)$ & $201.3(18.8)$ & $\begin{array}{l}1060.0 \\
(14.0)\end{array}$ & $\begin{array}{l}1119.4 \\
(66.4)\end{array}$ & $264.0(23.8)$ & $\begin{array}{l}1383.5 \\
(30.1)\end{array}$ \\
\hline & $\mathrm{H}$ & $891.9(47.9)$ & $265.4(35.2)$ & $1157.3(9.0)$ & $\begin{array}{l}1183.1 \\
(52.1)\end{array}$ & $339.3(20.6)$ & $\begin{array}{l}1522.4 \\
(22.2)\end{array}$ \\
\hline & $\mathrm{BIO}$ & $862.5(49.8)$ & $291.1(32.2)$ & $\begin{array}{l}1153.7 \\
(12.4)\end{array}$ & $\begin{array}{l}1151.3 \\
(68.9)\end{array}$ & $384.7(35.4)$ & $\begin{array}{l}1536.0 \\
(23.7)\end{array}$ \\
\hline & $\mathrm{H}+\mathrm{B} 10$ & $930.2(44.8)$ & $235.2(26.4)$ & $\begin{array}{l}1165.4 \\
(13.0)\end{array}$ & $\begin{array}{l}1206.4 \\
(58.5)\end{array}$ & $321.0(27.6)$ & $\begin{array}{l}1527.4 \\
(21.9)\end{array}$ \\
\hline \multicolumn{2}{|c|}{ LSD 5\% irrigation } & ns & 39.0 & 47.8 & ns & 65.1 & 56.7 \\
\hline \multicolumn{2}{|c|}{ LSD 5\% soil conditioners } & ns & 55.1 & 67.7 & ns & ns & 80.2 \\
\hline \multicolumn{2}{|c|}{ LSD 5\% Interaction } & ns & ns & ns & $\mathrm{ns}$ & $\mathrm{ns}$ & ns \\
\hline
\end{tabular}

From the data reported in Table 2, it is possible to notice a significant influence of the irrigation system adopted $(\operatorname{LSD} 5 \%=2.46)$, as well as of the soil conditioner (LSD 5\% $=3.48)$. No relevant effect of the combination between the two factors has been noticed.

As for the fresh herb response in Table 2, the effect of the irrigation system and of the type of conditioner used were relevant even in the case of the dry herb yield. Additionally, in this last case, a significant effect of the combination of the two main type of factors (irrigation system and soil conditioner) was observed (LSD 5\% interaction $=2.82$ ). This evidence suggests a different action of the soil conditioner depending on the irrigation system adopted. In more detail, looking at the last column on the right of Table 2, it is possible to appreciate a consistent variation of the dry herb yield during the second season depending on the irrigation system/soil conditioner combination. A consistent increase in the response can be observed in the case of the subsurface system which follows the trend $\mathrm{C}<\mathrm{H}<\mathrm{BIO}<\mathrm{H}+\mathrm{B} 10$. In the surface irrigation case, the trend is different: $\mathrm{C}<\mathrm{H} \leq \mathrm{BIO}=\mathrm{B} 10$.

As expected, the data reported in Table 4 are in agreement with the ones in Table 2. A significant influence of the irrigation system and of the soil conditioner was observed, while no relevant interaction was detected.

As for Tables 2 and 3, the data of Table 5 are aligned with the data of Table 3. A significant effect of each type of factor and a relevant interaction were observed. 
Table 5. Dry yield of Rosmarinus officinalis plants grown under different drip irrigation systems with different sources of soil conditioners. The medium values of three measurements are reported for each measurement.

\begin{tabular}{|c|c|c|c|c|c|c|c|}
\hline \multirow{3}{*}{\multicolumn{2}{|c|}{ Treatment }} & \multicolumn{6}{|c|}{ Fresh Yield (kg/Fad.) } \\
\hline & & \multirow{3}{*}{\multicolumn{2}{|c|}{$\begin{array}{c}\text { First Season } \\
\text { 1st Cut } \\
\text { Mean }( \pm) \\
72.7(13.0)\end{array}$}} & \multirow{3}{*}{$\begin{array}{c}\begin{array}{c}\text { 1st Cut } \\
\text { Mean }( \pm)\end{array} \\
279.1(4.5)\end{array}$} & \multirow{3}{*}{$\begin{array}{c}\begin{array}{c}\text { 1st Cut } \\
\text { Mean }( \pm)\end{array} \\
269.9(22.9)\end{array}$} & \multirow{2}{*}{$\begin{array}{c}\text { First Season } \\
\text { 1st Cut } \\
\text { Mean }( \pm)\end{array}$} & \multirow{2}{*}{$\begin{array}{l}\text { 1st Cut } \\
\text { Mean }( \pm)\end{array}$} \\
\hline & & & & & & & \\
\hline \multirow{4}{*}{ Surface } & $\mathrm{C}$ & & & & & 81.09 (12.6) & $350.98(7.2)$ \\
\hline & $\mathrm{H}$ & $208.9(15.3)$ & $110.6(13.2)$ & $319.5(1.5)$ & $278.7(29.6)$ & $\begin{array}{l}107.44 \\
(27.4)\end{array}$ & $386.2(1.5)$ \\
\hline & $\mathrm{BIO}$ & $203.2(20.2)$ & $105.5(15.6)$ & $308.7(3.2)$ & $267.2(28.6)$ & $\begin{array}{l}126.60 \\
(33.5)\end{array}$ & $393.8(3.4)$ \\
\hline & $\mathrm{H}+\mathrm{B} 10$ & $221.6(34.6)$ & $97.6(13.7)$ & $319.2(14.7)$ & $295.4(36.8)$ & $\begin{array}{l}103.70 \\
(10.8)\end{array}$ & $399.1(18.4)$ \\
\hline \multicolumn{2}{|c|}{ Surface irrigation } & $210.0(22.4)$ & $96.6(13.9)$ & $306.7(6.0)$ & $277.8(29.5)$ & $\begin{array}{l}104.71 \\
(21.1)\end{array}$ & $382.5(5.9)$ \\
\hline \multirow{4}{*}{ Subsurface } & $\mathrm{C}$ & $222.9(36.3)$ & $113.3(7.6)$ & $336.3(20.3)$ & $\begin{array}{l}289.83 \\
(42.2)\end{array}$ & $143.4(7.3)$ & $433.2(24.7)$ \\
\hline & $\mathrm{H}$ & $237.0(29.3)$ & $158.4(20.3)$ & $395.5(6.3)$ & $\begin{array}{l}312.84 \\
(37.1)\end{array}$ & $234.8(15.6)$ & $547.7(15.2)$ \\
\hline & $\mathrm{BIO}$ & $226.2(21.0)$ & $195.3(25.0)$ & $421.4(2.8)$ & $\begin{array}{l}308.57 \\
(23.8)\end{array}$ & $326.7(19.7)$ & $635.2(2.9)$ \\
\hline & $\mathrm{H}+\mathrm{B} 10$ & $243.4(19.5)$ & $15.9(19.1)$ & $396.3(0.2)$ & $\begin{array}{l}307.70 \\
(38.2)\end{array}$ & $267.6(28.6)$ & $575.3(6.8)$ \\
\hline \multicolumn{2}{|c|}{ Subsurface } & $232.4(26.5)$ & $155.0(18.0)$ & $387.4(6.0)$ & $\begin{array}{l}304.73 \\
(35.3)\end{array}$ & $243.1(17.8)$ & $547.8(12.4)$ \\
\hline \multirow{4}{*}{ Soil conditioners } & $\mathrm{C}$ & $214.7(27.8)$ & $93.0(10.3)$ & $307.7(12.4)$ & $279.9(32.6)$ & $112.2(10.0)$ & $392.1(16.0)$ \\
\hline & $\mathrm{H}$ & $223.0(22.3)$ & $134.5(16.7)$ & $357.5(3.9)$ & $295.8(33.3)$ & $171.1(21.5)$ & $466.9(8.4)$ \\
\hline & BIO & 214.7 (20.6) & $150.4(20.3)$ & $365.1(0.2)$ & $287.9(26.2)$ & $226.6(26.6)$ & $514.5(0.3)$ \\
\hline & $\mathrm{H}+\mathrm{B} 10$ & $232.5(27.0)$ & $125.2(16.4)$ & $357.8(7.5)$ & $301.6(37.5)$ & $185.6(19.7)$ & $487.2(12.6)$ \\
\hline LSD 5\% irr & tion & ns & 29.07 & 28.8 & ns & 29.2 & 32.5 \\
\hline \multirow{2}{*}{\multicolumn{2}{|c|}{$\begin{array}{l}\text { LSD 5\% soil conditioners } \\
\text { LSD 5\% Interaction }\end{array}$}} & ns & ns & 40.8 & ns & 41.3 & 46.0 \\
\hline & & ns & ns & ns & ns & 37.0 & 65.0 \\
\hline
\end{tabular}

$\mathrm{C}=$ control, $\mathrm{H}=\mathrm{HUNDZ}$ soil, BIO. = bentonite, $\mathrm{H}+\mathrm{B} 10=\mathrm{HUNDZ}$ soil + bentonite, $\Delta=$ standard deviation,

$\mathrm{LSD}=$ least significant differences, $\mathrm{ns}=$ not significant.

Analyzing the overall data of Tables 2-5, it is possible to notice that both fresh and dry herb yields (g/plant and $\mathrm{kg} / \mathrm{Fad}$.) were insignificantly affected by drip irrigation systems in the first cut during both seasons, while the different treatments had a pronounced effect during second cut as well as sum of two cuts during both seasons. Generally, subsurface system gave the highest values of fresh and dry herb weights. Different sources of soil amendments treatments had no significant effect on fresh herb and dry weights of herb ( $\mathrm{g} /$ plant and $\mathrm{kg} / \mathrm{acre})$ during the first cuts of both seasons. On the other hand, these treatments had a pronounced effect during the second cut and the sum of the 2 cuts of both seasons. During the first cut of both seasons, the HUNDZ soil + bentonite gave the highest values of fresh herb and dry weights of herb. Moreover, during the second cut, the fresh herb and dry weights of herb (g/plant and $\mathrm{kg} / \mathrm{acre}$ ) reached their maximum values as a result of bentonite treatment for both seasons. Regarding the effect of soil amendments on the total fresh and dry weights (sum of three cuts), the data reported in Tables 3-6 show that HUNDZ soil + bentonite and bentonite are advised for first and second seasons, respectively. The combined drip irrigation systems with different sources of soil amendments had no significant effect on the fresh herb and dry weights of herb during both seasons except for the herb dry weight for the second cut of the second season.

\subsection{EO Content (\%) and Yield (mL/Plant)}

During the first part of the study, it was possible to implement a water-saving irrigation system without affecting the plant in terms of plant/branch number and yield. In order to verify if the reduced amount of water and the specific soil conditioner employed affected the chemical composition of the plants, the corresponding essential oil (EO) was extracted and analyzed. 
The procedures of extraction and analysis are described in the experimental section at the end of the paper. The results obtained are expressed in terms of percentages $(\mathrm{EO} \%), \mathrm{EO} \mathrm{mL}$, and the amount of EO cultivated on a determined cultivated area, and were assessed as shown in Tables 6-8.

Table 6. Essential oil (EO) percentage of Rosmarinus officinalis plants grown under different drip irrigation systems with different sources of soil conditioners. The medium values of two extractions are reported for each measurement.

\begin{tabular}{|c|c|c|c|c|c|c|c|}
\hline \multirow{3}{*}{\multicolumn{2}{|c|}{ Treatment }} & \multicolumn{6}{|c|}{$\mathrm{EO} \%$} \\
\hline & & \multicolumn{3}{|c|}{ First Season } & \multicolumn{3}{|c|}{ First Season } \\
\hline & & 1st Cut & 1st Cut & 1st Cut & Ist Cut & 1st cut & 1st Cut \\
\hline \multirow{4}{*}{ Surface } & $\mathrm{C}$ & $3.63(0.06)$ & $3.75(0.13)$ & $7.38(0.05)$ & $3.63(0.03)$ & $3.73(0.09)$ & $7.36(0.04)$ \\
\hline & $\mathrm{H}$ & $3.75(0.13)$ & $3.85(0.03)$ & $7.60(0.07)$ & $3.72(0.11)$ & $3.81(0.02)$ & $7.53(0.06)$ \\
\hline & $\mathrm{BIO}$ & $3.92(0.03)$ & $3.94(0.01)$ & $7.86(0.01)$ & $3.90(0.03)$ & $3.93(0.04)$ & $7.83(0.01)$ \\
\hline & $\mathrm{H}+\mathrm{B} 10$ & $3.70(0.04)$ & $3.83(0.10)$ & $7.53(0.22)$ & $3.75(0.24)$ & $3.87(0.10)$ & $7.62(0.10)$ \\
\hline \multicolumn{2}{|c|}{ Surface irrigation } & $3.75(0.15)$ & $3.84(0.07)$ & $7.59(0.06)$ & $3.75(0.10)$ & $3.83(0.06)$ & $7.59(0.03)$ \\
\hline \multirow{4}{*}{ Subsurface } & $\mathrm{C}$ & $3.80(0.10)$ & $3.89(0.03)$ & $7.69(0.05)$ & $3.83(0.04)$ & $3.82(0.03)$ & $7.65(0.01)$ \\
\hline & $\mathrm{H}$ & $4.23(0.06)$ & $4.42(0.07)$ & $8.66(0.01)$ & $4.18(0.06)$ & $4.26(0.04)$ & $8.44(0.02)$ \\
\hline & BIO & $4.10(0.10)$ & $4.32(0.03)$ & $8.42(0.05)$ & $4.21(0.02)$ & $4.30(0.03)$ & $8.51(0.01)$ \\
\hline & $\mathrm{H}+\mathrm{B} 10$ & $4.03(0.15)$ & $4.23(0.10)$ & $8.26(0.04)$ & $4.04(0.21)$ & $4.21(0.04)$ & $8.25(0.13)$ \\
\hline \multicolumn{2}{|c|}{ Subsurface } & $4.04(0.10)$ & $4.22(0.06)$ & $8.26(0.03)$ & $4.06(0.08)$ & $4.15(0.03)$ & $8.21(0.04)$ \\
\hline \multirow{4}{*}{ Soil conditioners } & $\mathrm{C}$ & $3.72(0.08)$ & $3.82(0.08)$ & $7.54(0.00)$ & $3.73(0.03)$ & $3.78(0.06)$ & $7.50(0.02)$ \\
\hline & $\mathrm{H}$ & $3.99(0.10)$ & $4.14(0.05)$ & $8.13(0.03)$ & $3.95(0.09)$ & $4.03(0.03)$ & $7.98(0.04)$ \\
\hline & BIO & $4.01(0.06)$ & $4.13(0.02)$ & $8.14(0.03)$ & $4.06(0.02)$ & $4.12(0.03)$ & $8.17(0.01)$ \\
\hline & $\mathrm{H}+\mathrm{B} 10$ & $3.87(0.28)$ & $4.03(0.10)$ & $7.90(0.13)$ & $3.89(0.23)$ & $4.04(0.07)$ & $7.94(0.11)$ \\
\hline \multicolumn{2}{|c|}{ LSD 5\% irrigation } & 0.14 & 0.06 & 0.19 & 0.11 & 0.05 & 0.13 \\
\hline \multicolumn{2}{|c|}{ LSD 5\% soil conditioners } & 0.20 & 0.09 & 0.26 & 0.15 & 0.07 & 0.18 \\
\hline \multicolumn{2}{|c|}{ LSD 5\% Interaction } & ns & 0.29 & ns & ns & 0.09 & 0.25 \\
\hline
\end{tabular}

$\mathrm{C}=$ control, $\mathrm{H}=\mathrm{HUNDZ}$ soil, $\mathrm{BIO}$. = bentonite, $\mathrm{H}+\mathrm{B} 10=\mathrm{HUNDZ}$ soil + bentonite, $\Delta=$ standard deviation, $\mathrm{LSD}=$ least significant differences, $\mathrm{ns}=$ not significant.

Table 7. EO content of Rosmarinus officinalis plant grown under different drip irrigation systems with different sources of soil conditioners. The medium values of two extractions are reported for each measurement.

\begin{tabular}{|c|c|c|c|c|c|c|c|}
\hline \multirow{3}{*}{\multicolumn{2}{|c|}{ Treatment }} & \multicolumn{6}{|c|}{ EO (mL/plant) } \\
\hline & & \multicolumn{3}{|c|}{ First Season } & \multicolumn{3}{|c|}{ First Season } \\
\hline & & Mean $( \pm)$ & Mean $( \pm)$ & Mean $( \pm)$ & Mean $( \pm)$ & Mean $( \pm)$ & Mean $( \pm)$ \\
\hline \multirow{4}{*}{ Surface } & C & $0.33(0.03)$ & $0.12(0.03)$ & $0.44(0.00)$ & $0.43(0.03)$ & $0.13(0.02)$ & $0.56(0.01)$ \\
\hline & $\mathrm{H}$ & $0.34(0.03)$ & $0.19(0.02)$ & $0.53(0.01)$ & $0.45(0.05)$ & $0.18(0.05)$ & $0.63(0.01)$ \\
\hline & $\mathrm{BIO}$ & $0.35(0.08)$ & $0.18(0.03)$ & $0.53(0.03)$ & $0.45(0.09)$ & $0.22(0.06)$ & $0.67(0.02)$ \\
\hline & $\mathrm{H}+\mathrm{B} 10$ & $0.36(0.09)$ & $0.16(0.03)$ & $0.52(0.05)$ & $0.48(0.09)$ & $0.17(0.02)$ & $0.66(0.05)$ \\
\hline \multicolumn{2}{|c|}{ Surface irrigation } & $0.34(0.06)$ & $0.16(0.03)$ & $0.51(0.02)$ & $0.45(0.07)$ & $0.18(0.04)$ & $0.63(0.02)$ \\
\hline \multirow{4}{*}{ Subsurface } & $\mathrm{C}$ & $0.37(0.06)$ & $0.19(0.01)$ & $0.56(0.04)$ & $0.48(0.09)$ & $0.24(0.01)$ & $0.72(0.06)$ \\
\hline & $\mathrm{H}$ & $0.44(0.12)$ & $0.30(0.04)$ & $0.74(0.06)$ & $0.57(0.14)$ & $0.43(0.10)$ & $1.00(0.03)$ \\
\hline & BIO & $0.40(0.10)$ & $0.37(0.05)$ & $0.77(0.03)$ & $0.57(0.13)$ & $0.61(0.04)$ & $1.18(0.06)$ \\
\hline & $\mathrm{H}+\mathrm{B} 10$ & $0.43(0.04)$ & $0.28(0.03)$ & $0.71(0.01)$ & $0.54(0.09)$ & $0.49(0.11)$ & $1.03(0.01)$ \\
\hline \multicolumn{2}{|c|}{ Subsurface } & $0.41(0.08)$ & $0.29(0.03)$ & $0.69(0.03)$ & $0.54(0.11)$ & $0.44(0.06)$ & $0.98(0.03)$ \\
\hline \multirow{4}{*}{ Soil conditioners } & C & $0.35(0.04)$ & $0.16(0.02)$ & $0.50(0.02)$ & $0.45(0.06)$ & $0.19(0.02)$ & $0.64(0.03)$ \\
\hline & $\mathrm{H}$ & $0.39(0.07)$ & $0.24(0.03)$ & $0.63(0.03)$ & $0.51(0.10)$ & $0.31(0.07)$ & $0.82(0.02)$ \\
\hline & $\mathrm{BIO}$ & $0.37(0.09)$ & $0.27(0.04)$ & $0.65(0.03)$ & $0.51(0.11)$ & $0.41(0.05)$ & $0.92(0.04)$ \\
\hline & $\mathrm{H}+\mathrm{B} 10$ & $0.39(0.07)$ & $0.22(0.03)$ & $0.62(0.03)$ & $0.51(0.09)$ & $0.33(0.07)$ & $0.85(0.02)$ \\
\hline \multicolumn{2}{|c|}{ LSD 5\% irrigation } & ns & 0.05 & 0.07 & 0.08 & 0.05 & 0.09 \\
\hline \multicolumn{2}{|c|}{ LSD 5\% soil conditioners } & ns & 0.07 & 0.1 & ns & 0.07 & 0.12 \\
\hline \multicolumn{2}{|c|}{ LSD 5\% Interaction } & ns & ns & $\mathrm{ns}$ & $\mathrm{ns}$ & 0.10 & ns \\
\hline
\end{tabular}

$\mathrm{C}=$ control, $\mathrm{H}=\mathrm{HUNDZ}$ soil, $\mathrm{BIO}$. = bentonite, $\mathrm{H}+\mathrm{B} 10=\mathrm{HUNDZ}$ soil + bentonite, $\Delta=$ standard deviation, $\mathrm{LSD}=$ least significant differences, $\mathrm{ns}=$ not significant. 
Table 8. EO yield of Rosmarinus officinalis plants grown under different drip irrigation systems with different sources of soil conditioners. The medium values of two extractions are reported for each measurement.

\begin{tabular}{|c|c|c|c|c|c|c|c|}
\hline \multirow{3}{*}{\multicolumn{2}{|c|}{ Treatment }} & \multicolumn{6}{|c|}{ EO (L/Fad.) } \\
\hline & & \multirow{2}{*}{$\begin{array}{c}\text { 1st Cut } \\
\text { Mean }( \pm)\end{array}$} & \multirow{3}{*}{$\begin{array}{c}\text { First Season } \\
\text { 1st Cut } \\
\text { Mean ( } \pm \text { ) }\end{array}$} & \multirow{3}{*}{$\begin{array}{c}\begin{array}{c}\text { 1st Cut } \\
\text { Mean }( \pm)\end{array} \\
10.2(0.1)\end{array}$} & \multirow{3}{*}{$\begin{array}{c}\begin{array}{c}\text { 1st Cut } \\
\text { Mean ( }( \pm)\end{array} \\
9.8(0.8)\end{array}$} & \multirow{2}{*}{$\begin{array}{c}\text { First Season } \\
\text { 1st Cut } \\
\text { Mean }( \pm)\end{array}$} & \multirow{2}{*}{$\begin{array}{c}\text { 1st Cut } \\
\text { Mean }( \pm)\end{array}$} \\
\hline & & & & & & & \\
\hline \multirow{4}{*}{ Surface } & $\mathrm{C}$ & $7.5(0.6)$ & & & & $3.0(0.5)$ & $12.8(0.2)$ \\
\hline & $\mathrm{H}$ & $7.8(0.7)$ & $4.3(0.5)$ & $12.1(0.1)$ & $10.4(1.2)$ & $4.1(1.0)$ & $14.5(0.1)$ \\
\hline & $\mathrm{BIO}$ & $8.0(1.7)$ & $4.2(0.6)$ & $12.1(0.8)$ & $10.4(2.0)$ & $5.0(1.3)$ & $15.4(0.4)$ \\
\hline & $\mathrm{H}+\mathrm{B} 10$ & $8.3(2.2)$ & $3.7(0.6)$ & $12.0(1.1)$ & $11.1(2.1)$ & $4.0(0.5)$ & $15.2(1.1)$ \\
\hline \multicolumn{2}{|c|}{ Surface irrigation } & $7.9(1.3)$ & $3.7(0.6)$ & $11.6(0.5)$ & $10.4(1.5)$ & $4.0(0.9)$ & $14.5(0.5)$ \\
\hline \multirow{4}{*}{ Subsurface } & $\mathrm{C}$ & $8.4(1.5)$ & $4.4(0.3)$ & $12.8(0.8)$ & $11.1(2.2)$ & $5.5(0.3)$ & $16.6(1.3)$ \\
\hline & $\mathrm{H}$ & $10.0(2.7)$ & $7.0(0.9)$ & $17.0(1.3)$ & $13.0(3.2)$ & $10.0(2.2)$ & $23.1(0.7)$ \\
\hline & $\mathrm{BIO}$ & $9.2(2.2)$ & $8.4(1.1)$ & $17.7(0.7)$ & $13.0(3.0)$ & $14.1(0.9)$ & $27.1(1.4)$ \\
\hline & $\mathrm{H}+\mathrm{B} 10$ & $9.8(0.9)$ & $6.5(0.7)$ & $16.3(0.1)$ & $12.5(2.0)$ & $11.3(2.5)$ & $23.7(0.3)$ \\
\hline \multicolumn{2}{|c|}{ Subsurface } & $9.4(1.8)$ & $6.6(0.7)$ & $16.0(0.7)$ & $12.4(2.6)$ & $10.2(1.5)$ & $22.6(0.9)$ \\
\hline \multirow{4}{*}{ Soil conditioners } & C & $8.0(1.0)$ & $3.6(0.4)$ & $11.5(0.4)$ & $10.4(1.5)$ & $4.3(0.4)$ & $14.7(0.7)$ \\
\hline & $\mathrm{H}$ & $8.9(1.7)$ & $5.6(0.7)$ & $14.6(0.7)$ & $11.7(2.2)$ & $7.0(1.6)$ & $18.8(0.4)$ \\
\hline & $\mathrm{BIO}$ & $8.6(2.0)$ & $6.3(0.9)$ & $14.9(0.8)$ & $11.7(2.5)$ & $9.5(1.1)$ & $21.2(0.9)$ \\
\hline & $\mathrm{H}+\mathrm{B} 10$ & $9.1(1.5)$ & $5.1(0.7)$ & $14.2(0.6)$ & $11.8(2.1)$ & $7.6(1.5)$ & $19.4(0.4)$ \\
\hline \multicolumn{2}{|c|}{ LSD $5 \%$ irrigation } & ns & 1.2 & 1.6 & 1.9 & 1.2 & 2.0 \\
\hline \multicolumn{2}{|c|}{ LSD 5\% soil conditioners } & ns & 1.7 & 2.3 & ns & 1.7 & 2.8 \\
\hline \multicolumn{2}{|c|}{ LSD 5\% Interaction } & ns & ns & ns & ns & 2.4 & ns \\
\hline
\end{tabular}

$\mathrm{C}=$ control, $\mathrm{H}=\mathrm{HUNDZ}$ soil, $\mathrm{BIO}$. = bentonite, $\mathrm{H}+\mathrm{B} 10=\mathrm{HUNDZ}$ soil + bentonite, $\Delta=$ standard deviation, $\mathrm{LSD}=$ least significant differences, $\mathrm{ns}=$ not significant.

The data obtained revealed that the EO content (\%) and yield (mL/plant and $\mathrm{kg} / \mathrm{Fad}$.) are affected by the drip irrigation systems, the different sources of soil amendment and by the combined effect of both factors (Tables 6-8). A mean comparison between both drip irrigation systems showed that the highest EO content $(\%)$ and yield ( $\mathrm{mL} /$ plant or L/acre) were obtained from plants grown under subsurface irrigation systems. This observation is in agreement with the previous reported data relative to the growth parameters and confirms the possibility to grow a good quality Rosmarinus officinalis plant with a minimum amount of water.

Concerning the effect of different sources of soil amendment, the data presented in the same tables indicate that HUNDZ soil and HUNDZ soil + bentonite gave the highest mean value of EO content (\%) for the first cut of the first season while bentonite alone gave the maximum value of EO percentage for the second cut and total (sum of both cuts) of both seasons. The combination between drip irrigation systems and soil amendments had no significant effect on the EO percentage except during the second cut of the second season. Generally, plants grown on bentonite under a subsurface irrigation system gave the maximum mean value of EO percentage during both seasons except during the first cut of the first season.

Concerning the effect of drip irrigation systems, different sources of soil amendments on the EO yield (mL/plant and L/Fad.) — data tabulated in Tables 7 and 8 -indicate that the effect of these treatments showed a trend similar to the one observed in the case of the EO percentage.

\subsection{Composition of the $E O$}

The EO extracted from plants subjected to different treatments revealed the presence of twenty-four compounds, which accounted for more than $95 \%$ of the overall chemical composition detected by GC-MS (Table 9). 
Table 9. Main constituents of the EOs of Rosmarinus officinalis plants grown under different drip irrigation systems with different sources of soil conditioners.

\begin{tabular}{|c|c|c|c|c|c|c|c|c|c|}
\hline \multirow{2}{*}{ Name } & \multirow{2}{*}{ KI } & \multicolumn{4}{|c|}{ Surface } & \multicolumn{4}{|c|}{ Subsurface } \\
\hline & & $\mathrm{C}$ & $\mathrm{HZ}$ & BENT & $\mathrm{HZ}+\mathrm{BENT}$ & $\mathrm{C}$ & $\mathrm{HZ}$ & BENT & $\mathrm{HZ}+\mathrm{BENT}$ \\
\hline Tricyclene & 900 & 0.2 & 0.2 & 0.2 & 0.2 & 0.1 & 0.2 & 0.2 & 0.1 \\
\hline$\alpha$-Pinene & 909 & 19.3 & 16.7 & 16.8 & 21.1 & 14.5 & 18.8 & 20.6 & 15.4 \\
\hline Camphene & 927 & 4.8 & 4.7 & 4.6 & 4.8 & 4.4 & 4.8 & 4.7 & 4.2 \\
\hline thuja 2,4-Diene & 930 & 0.4 & 0.5 & 0.5 & 0.4 & 0.5 & 0.5 & 0.4 & 0.4 \\
\hline$\beta$-Pinene & 956 & 0.5 & 0.4 & 0.4 & 0.6 & 0.4 & 0.4 & 0.5 & 0.3 \\
\hline$\beta$-Myrcene & 957 & 0.7 & 0.5 & 0.5 & 0.8 & 0.5 & 0.5 & 0.6 & 0.4 \\
\hline Phellandrene & 984 & 0.3 & 0.2 & 0.2 & 0.3 & 0.2 & 0.2 & 0.3 & 0.2 \\
\hline$\delta$-2-Carene & 1005 & 0.7 & 0.6 & 0.6 & 0.7 & 0.6 & 0.6 & 0.7 & 0.5 \\
\hline p-cymene & 1026 & 1.1 & 0.9 & 0.9 & 1.2 & 1.0 & 0.9 & 1.0 & 0.8 \\
\hline Eucalyptol & 1036 & 14.5 & 14.5 & 14.4 & 15.5 & 14.4 & 14.1 & 13.7 & 13.1 \\
\hline$\gamma$-Terpinene & 1062 & 1.0 & 0.8 & 0.74 & 1.0 & 0.8 & 0.7 & 0.9 & 0.5 \\
\hline Terpinolene & 1065 & 1.4 & 1.1 & 1.0 & 1.3 & 1.1 & 1.0 & 1.2 & 0.9 \\
\hline Linalool & 1102 & 1.0 & 1.0 & 1.0 & 1.1 & 1.0 & 0.9 & 1.1 & 0.9 \\
\hline$\alpha$-Campholenal & 1106 & 0.5 & 0.4 & 0.5 & 0.5 & 0.5 & 0.4 & 0.4 & 0.3 \\
\hline Camphor & 1145 & 40.0 & 44.1 & 44.3 & 40.7 & 44.0 & 41.9 & 38.6 & 44.8 \\
\hline Pinocarvone & 1161 & 0.2 & 0.1 & 0.1 & 0.3 & 0.3 & 0.3 & 0.3 & 0.1 \\
\hline Terpinen-4-ol & 1163 & 0.9 & 0.9 & 0.9 & 0.7 & 1.0 & 0.9 & 0.9 & 2.3 \\
\hline Thymol & 1165 & 0.1 & 0.1 & 0.2 & 0.9 & 0.8 & 0.8 & 0.9 & 0.1 \\
\hline$\alpha$-Terpineol & 1180 & 2.5 & 2.2 & 2.3 & 2.1 & 2.5 & 2.2 & 2.4 & 3.3 \\
\hline Verbenone & 1223 & 7.8 & 6.9 & 7.1 & 5.2 & 9.1 & 7.7 & 7.9 & 6.3 \\
\hline Bornyl acetate & 1261 & 0.4 & 0.4 & 0.3 & 0.1 & 0.3 & 0.4 & 0.4 & 0.2 \\
\hline Caryophyllene & 1400 & 0.2 & 0.2 & 0.3 & - & 0.3 & 0.2 & 0.2 & 0.2 \\
\hline$\alpha$-Humulene & 1406 & 0.4 & 0.3 & 0.4 & - & 0.4 & 0.4 & 0.4 & 0.1 \\
\hline Bisabolene, trans- & 1479 & 0.1 & 0.2 & 0.0 & - & 0.1 & 0.1 & - & 0.1 \\
\hline \multicolumn{2}{|c|}{ Monoterpene hydrocarbons } & 30.4 & 26.7 & 26.4 & 32.3 & 24.1 & 28.6 & 31.2 & 23.7 \\
\hline \multicolumn{2}{|c|}{ Oxygenated hydrocarbons } & 68.0 & 70.8 & 71.0 & 67.2 & 74.0 & 69.6 & 66.6 & 71.5 \\
\hline \multicolumn{2}{|c|}{ Sesquiterpene hydrocarbons } & 0.7 & 0.8 & 0.7 & 0.0 & 0.8 & 0.7 & 0.7 & 0.3 \\
\hline \multicolumn{2}{|c|}{ Total of identified compounds } & 99.1 & 98.2 & 98.2 & 99.5 & 98.9 & 98.9 & 98.4 & 95.6 \\
\hline \multicolumn{2}{|c|}{ Unidentified compounds } & 0.9 & 1.8 & 1.8 & 0.4 & 1.1 & 1.1 & 1.6 & 4.4 \\
\hline
\end{tabular}

The unidentified compounds ranged from 0.9 to $4.4 \%$ from the separated compounds. The major constituents of EO samples were camphor (38.6-44.8\%), $\alpha$-pinene $(14.5-21.1 \%)$ and then eucalyptol (13.1-15.5\%).

Recently, Melito et al. [26] studied the chemical composition of Rosmarinus officinalis EOs extracted from Sardinian plants. The authors evidenced a great variability in composition according to meteorological and environmental conditions and several chemo types were identified. Their chemical analysis highlighted the presence of seven major compounds among which $\alpha$-pinene which ranged between 26 and $28 \%$, champhene between 5 and 8\%, 1,8-cineole between 15 and 25\%, borneol between 5 and $11 \%$, camphor between 3 and $12 \%$, verbenone between 6 and $15 \%$ and bornyl acetate between 4 and $7 \%$. According to these results the different chemical composition between Sardinian and Egyptian EOs could be related to the different geographical area of cultivation as well as the different environmental contest.

As reported in Table 9, the monoterpene fractions seem to be affected by the irrigation system and soil conditioner. In fact, in the surface-irrigated samples, both HUNDZ soil and bentonite clay used alone induced an increment in the oxygenated monoterpenes if compared to the control and to the HUNDZ + bentonite treated samples. The opposite trend was observed for the samples subjected to subsurface dripping. The biosynthesis of secondary metabolites in plants is very complex and our results suggest a slight dependence on the synthesis of terpenoids according to the different irrigation system and the soil conditioner used. Nevertheless, at the moment, it is not possible to suggest any specific pathway promoted by the type of irrigation.

In general, subsurface drip irrigation systems are more efficient at satisfying the water and nutrient requirements of the plants and minimizing the water losses. This is due to the particular engineering layout of such systems: it consists of buried drip tubes which deliver water directly under the surface and close to the roots. This avoids any surface water evaporation and at the same time reduces weeds and diseases. This configuration requires the higher initial investment with respect to other 
classic techniques, with a specific cost that depends on the water source, quality, and filtration needs, choice of material, soil characteristics and degree of automation desired.

Although the subsurface irrigation system has been known since the 1960s, it has only been consistently used during the last 20 years. In addition to the previous described advantages (vide infra), this system is particularly suitable in arid and semi-arid lands where water harvesting is of primary importance. Additionally, as it is placed under the surface, it is not affected by wind or other atmospheric issues, and the upper ground available for any operation.

From the other side, considerable improvements to the roots' environment can be achieved by the employment of opportune soil conditioners. The positive effects of soil modification can be directed to the definition of a different soil structure, water holding ability, availability of nutrients, and, in general, to the assessment of better living conditions for all the microorganisms related to plant growth. As there is a symbiosis between soil and plants, the presence of healthy roots reduces soil degradation, especially in the case of extreme weather (heavy rain or wind). In general, soil properties can be modified not only adding specific substances, but also by growing dedicated cultivations, which are also considered soil amendments.

By using a soil amendment, almost every type of soil can be made fertile. Bentonite, historically employed for clarification procedures [43], is a volcanic ash rock consisting predominantly of montmorillonite, a clay mineral of $\mathrm{Mg}$ and $\mathrm{Al}$ which determine the peculiar structural properties of the material [44]. It has also been recognized as a very good material for the improvement of coarse textured soils in different parts of the world [45].

\section{Conclusions}

Aromatic plant cultivation in arid and semi-arid regions can be achieved in a sustainable and effective way, with a special emphasis on water consumption and the quality of growth parameters. In the specific case of Rosmarinus officinalis L., it was possible to determine the improved cultivar conditions by selecting a combination of subsurface irrigation systems and HUNDZ-bentonite soil conditioners. In particular, by switching from surface to subsurface irrigation systems and by employing as a soil conditioner a combination of HUNDZ conditioner and bentonite, it was possible to reach the same plant quality as usual whilst saving a consistent amount of water. This notable result was assessed both in terms of plant growth parameters, as well as in terms of chemical composition, determined by extracting the essential oil and subjecting it to a GC-MS analysis. The presented approach herein, based on the study of the correlation between growth parameters and chemical compositions, and growth procedure, can be further extended to other cultivations.

Author Contributions: Conceptualization, E.O.; methodology S.H.; formal analysis, G.L.P.; investigation, A.N.E.; resources, E.O.; data curation, A.M.; writing-original draft preparation, E.O. and S.H.; writing-review and editing, A.M.; supervision, G.P.; project administration, E.O.; funding acquisition, E.O. and G.P. All authors have read and agreed to the published version of the manuscript.

Funding: This research received no external funding.

Acknowledgments: This work was supported from the National Research Centre, Egypt (Project No. 10120106).

Conflicts of Interest: The authors declare no conflict of interest.

\section{References}

1. Falkenmark, M.; Lindh, G. Water For a Starving World, 1st ed.; Routledge: Abingdon, UK, 2019; ISBN-13: 978-0367213183.

2. Fahmy, S.; Ezzat, M.; Shalby, A.; Kandil, H.; Sharkawy, M.; Allam, M.; Assiouty, I.; Tczap, A. Water Policy Review and Integration Study; Report No. 65; Ministry of Water Resources and Irrigation: Cairo, Egypt, 2002.

3. Kang, S.Z.; Shi, P.; Pan, Y.H.; Liang, Z.S.; Hu, X.T.; Zhang, J. Soil water distribution, uniformity and water-use efficiency under alternate furrow irrigation in arid areas. Agric. Water Manag. 2000, 19, 181-190. [CrossRef] 
4. Molden, D.J.; El-Kady, M.; Zhu, Z. Use and productivity of Egypt's Nile water. In Contemporary Challenges for Irrigation and Drainage, Proceedings of the USCID 14th Technical Conference on Irrigation, Drainage and Flood Control, Phoenix, AZ, USA, 3-6 June 1998; Burns, I.J., Anderson, S.S., Eds.; USCID: Denver, CO, USA, 1998.

5. Petretto, G.L.; Urgeghe, P.P.; Massa, D.; Melito, S. Effect of salinity (NaCl) on plant growth, nutrient content, and glucosinolate hydrolysis products trends in rocket genotypes. Plant. Physiol. Biochem. 2019, 141, 30-39. [CrossRef]

6. Ashour, A.; El Attar, S.T.; Rafaat, Y.M.; Mohamed, M.N. Water Resources Management in Egypt. J. Eng. Sci. Assiut Univ. 2009, 37, 269-279.

7. Annex I: Irrigation Efficiencies. Available online: http://www.fao.org/3/t7202e/t7202e08.htm (accessed on 28 April 2020).

8. Phene, C.J.; Davis, K.R.; Hutmacher, R.B.; Yosef, B.; Meek, D.W. Effect of high frequency surface and subsurface drip irrigation on root distribution of sweet corn. Irr. Sci. 1991, 12, 135-140. [CrossRef]

9. Al-Jamal, M.S.; Ball, S.; Sammis, T.W. Comparison of sprinkler, trickle and furrow irrigation efficiencies for onion production. Agric. Water Manag. 2001, 46, 253-266. [CrossRef]

10. Zhao, R.H.; He, W.-Q.; Lou, Z.-K.; Nie, W.-B.; Ma, X.-Y. Synchronization Optimization of Pipeline Layout and Pipe Diameter Selection in a Self-Pressurized Drip Irrigation Network System Based on the Genetic Algorithm. Water 2019, 11, 489. [CrossRef]

11. Kumar, R.R.; Sriram, K.; Narayanan, I.S. Self Optimizing Drip Irrigation System Using Data Acquisition and Virtual Instrumentation to Enhance the Usage of Irrigation Water, Lecture Notes in Networks and Systems. In Cyber-Physical Systems and Digital Twins; REV2019; Auer, M., Ram, B.K., Eds.; Springer: Cham, Germany, 2019; Volume 80.

12. Hanson, B.; May, D. Effect of subsurface drip irrigation on processing tomato yield, water table depth, soil salinity, and profitability. Agric. Water Manag. 2004, 68, 1-17. [CrossRef]

13. Suganya, S.; Sivasamy, R. Moisture retention and cation exchange capacity of sandy soil as influenced by soil additives. J. Appl. Sci. Res. 2006, 2, 949-951.

14. Mansour, H.A.; Gaballah, M.S.; Abd El-Hady, M.; Ebtisam, I. Influence of different localized irrigation systems and treated agricultural wastewater on distribution uniformities, potato growth, tuber yield and water use efficiency. J. Agric. Sci. 2014, 2, 143-150.

15. Mansour, H.A.-G.; Tayel, M.Y.; Abd El-Hady, M.A.; Lightfoot, D.A.; El-Gindy, A.M. Modification of water application uniformity among closed circuit trickle irrigation systems. Agric. Sci. 2010, 1, 1-9. [CrossRef]

16. Ahmed, E.M.; Barakat, M.M.A.; Ragheb, H.M.; Rushdi, M.K. Impact of Surface and Subsurface Drip Irrigation Systems and Fertigation Managements on Yield and Water Use Efficiencies of Two Squash Varieties. Assiut J. Agric. Sci. 2017, 48, 303-318.

17. Oron, G.; DeMalach, Y.; Gillerman, L.; David, I.; Rao, V.P. Improved saline-Water use under subsurface drip irrigation. Agric. Water Manag. 1998, 39, 19-33. [CrossRef]

18. Oliveira, M.R.G.; Calado, A.M.; Portas, C.A.M. Tomato root distribution under drip irrigation. J. Am. Soc. Hort. Sci. 1996, 121, 644-648. [CrossRef]

19. Grabow, G.L.; Huffman, R.L.; Edmisten, K. Automated Control of Subsurface Drip Irrigation Using Rainfall and Soil Water Data; ASAE Paper No. 042190; ASAE: St. Joseph, MI, USA, 2004.

20. Gengoglan, C.; Altunbey, H.; Gengoglan, S. Response of green bean (phaseolus vulgaris L.) to subsurface drip irrigation and partial rootzone drying irrigation. Agric. Water Manag. 2006, 84, 274-280. [CrossRef]

21. El-Shawadfy, M. Influence of Different Irrigation Systems and Treatments on Productivity and Fruit Quality of Some Bean Varieties. Master's Thesis, Ain Shams University, Cairo, Egypt, 2008.

22. Camp, C.R. Subsurface drip irrigation: A review. Trans. ASAE 1998, 41, 1353-1367. [CrossRef]

23. Singh, D.K.; Rajput, T.B.S. Response of lateral placement depths of subsurface drip irrigation on okra (Abelmoschus esculentus). Int. J. Plant. Prod. 2007, 1, 73-84.

24. Lamm, F.R.; Manges, H.L.; Stone, L.R.; Khan, A.H.; Rogers, D.H. Water requirement of subsurface drip-irrigated corn in northwest Kansas. Trans. ASAE 1995, 38, 441-448. [CrossRef]

25. Maldini, M.; Montoro, P.; Addis, R.; Toniolo, C.; Petretto, G.L.; Foddai, M.; Nicoletti, M.; Pintore, G. A new approach to discriminate Rosmarinus officinalis L. plants with antioxidant activity, based on HPTLC fingerprint and targeted phenolic analysis combined with PCA. Ind. Crop. Prod. 2016, 94, 665-672. [CrossRef]

26. Melito, S.; Petretto, G.L.; Chahine, S.; Pintore, G.; Chessa, M. Seasonal Variation of Essential Oil in Rosmarinus officinalis Leaves in Sardinia. Nat. Prod. Com. 2019, 14, 7. [CrossRef] 
27. Khorshidi, J.; Mohammadi, R.; Fakhr, M.T.; Nourbakhsh, H. Influence of Drying Methods, Extraction Time, and Organ Type on Essential Oil Content of Rosemary (Rosmarinus officinalis L.). Nat. Sci. 2009, 7, $42-44$.

28. Moreno, S.; Scheyer, T.; Romano, C.S.; Vojnov, A. Antioxidant and antimicrobial activities of rosemary extracts linked to their polyphenol composition. Free Radic. Res. 2006, 40, 223-231. [CrossRef] [PubMed]

29. Wang, W.; Wu, N.; Zu, Y.; Fu, Y. Antioxidative activity of Rosmarinus officinalis L. essential oil compared to its main components. Food Chem. 2008, 108, 1019-1022. [CrossRef] [PubMed]

30. Rozman, T.; Jersek, B. Antimicrobial activity of rosemary extracts (Rosmarinus officinalis L.) against different species of Listeria. Acta Agric. Slov. 2004, 93, 51-58.

31. Moghtader, M.; Afzali, D. Study of the antibacterial properties of the essential oil of Rosemary. Am. Eur. J. Agric. Environ. Sci. 2009, 5, 393-397.

32. Papachristos, D.P.; Stampoulos, D.C. Fumigant toxicity of three essential oils on the eggs of Acanthoscelide sobtectus (Say) (Coleoptera: Bruchidae). J. Stored Prod. Res. 2004, 40, 517-525. [CrossRef]

33. Cuman, R.K. Anti-Inflammatory and Antinociceptive Effects of Rosmarinus officinalis L. Essential Oil in Experimental Animal Models. J. Med. Food. 2008, 11, 741-746.

34. Takaki, I.; Bersani-Amado, L.E.; Vendruscolo, A.; Sartoretto, S.M.; Diniz, S.P.; Bersani-Amado, C.A.; Tunc, I.; Berger, B.M.; Erler, F.; Dagli, F. Ovicidal activity of essential oils from plants against two stored-product insects. J. Stored Prod. Res. 2000, 36, 161-168.

35. Ozcan, M.M.; Chalchat, J. Chemical composition and antifungal activity of rosemary (Rosmarinus officinalis L) oil from Turkey. Int. J. Food Sci. Nutr. 2008, 59, 691-698. [CrossRef]

36. Pozzatti, P.; Alves Scheid, L.; Borba Spader, T.; Linde Atayde, M.; Morais Santurio, J.; Hartz Alves, S. In vitro activity of essential oils extracted from plants used as spices against fluconazole-resistant and fluconazole-susceptible Candida spp. Can. J. Microbiol. 2008, 54, 950-956. [CrossRef]

37. Isman, M.B. Plant essential oils for pest and disease management. Crop. Prot. 2000, 19, 603-608. [CrossRef]

38. Jones, B.; Nachtscheim, C.J. Split-Plot Designs: What, Why, and How. J. Quality Technol. 2009, 41, 340-361. [CrossRef]

39. Petretto, G.L.; Fancello, F.; Zara, S.; Foddai, M.; Mangia, N.P.; Sanna, M.L.; Omer, E.A.; Menghini, L.; Chessa, M.; Pintore, G. Antimicrobial Activity against Beneficial Microorganisms and Chemical Composition of Essential Oil of Mentha suaveolens ssp. insularis Grown in Sardinia. J. Food Sci. 2014, 79, 369-377. [CrossRef] [PubMed]

40. Mannu, A.; Melito, S.; Petretto, G.L.; Manconi, P.; Pintore, G.M.; Chessa, M. Geographical variation of the chemical composition in essential oils extracted from Sardinian Salvia verbenaca. Nat. Prod. Res. 2020. [CrossRef] [PubMed]

41. Phene, C.J.; De Tar, W.R.; Clark, D.A. Real time irrigation scheduling of cotton with an automated pan evaporation system. Appl. Eng. Agric. 1992, 8, 787-793. [CrossRef]

42. Bidondo, D.; Andreau, R.; Martinez, S.; Garbi, M.; Chale, W.; Cremaschi, G. XXVIII International Horticultural Congress on Science and Horticulture for People (IHC2010): Comparison of the effect of surface and subsurface drip irrigation on water use growth and production of a greenhouse tomato crop. In Proceedings of the International Symposium on Greenhouse 2010 and Soilless Cultivationm, Lisbon, Portugal, 22 August 2010; pp. 309-313.

43. Mannu, A.; Vlahopoulou, G.; Sireus, V.; Petretto, G.L.; Mulas, G.; Garroni, S. Bentonite as a Refining Agent in Waste Cooking Oils Recycling: Flash Point, Density and Color Evaluation. Nat. Prod. Commun. 2018, 13, 613-616. [CrossRef]

44. Varma, R.S. Clay and clay-supported reagents in inorganic synthesis. Tetrahedron 2002, 58, 1235-1255. [CrossRef]

45. Satje, A.; Nelson, P. Bentonite treatments can improve the nutrient and water holding capacity of sugarcane soils in the wet tropics. Proc. Aust Soc. Sugarcane Technol. 2009, 31, 166-176.

Sample Availability: Samples of the compounds are not available.

(C) 2020 by the authors. Licensee MDPI, Basel, Switzerland. This article is an open access article distributed under the terms and conditions of the Creative Commons Attribution (CC BY) license (http://creativecommons.org/licenses/by/4.0/). 